\section{Noise-LeVEl Measurements}

In connexion with problems of noise abatement, the National Physical Laboratory has made measurements and analyses of many noises of very varied origin. The positions which $\mathrm{s}$ sme of these noises occupy in a scale of phons $\varepsilon$ re shown in Fig. 1, the upper half of which inc udes various noises the abatement of which would se acceptable in many circumstances. This is illustrated by the homely test which most of us apply as a test of background of noise, namely, the ease with which conversation is possible. At 60 phons, conversation is 'comfortable'; at 90 phons, difficult; and at 110 phons, virtually impossible.

Among the noise problems on which the Laboratory has been consulted in recent years, are the mitigation of the noises associated with aeroplane cabins and engine-testing factories, trains, ships, tube railways, buses, motor horns, pneumatic drills, printing works, transformer substations, cathedrals, assembly halls, business offices, flats, miniature rifle ranges, building operations, and so on. Assistance is also being given in connection with the Home Office experiments on air-raid warnings.

The loudness of a noise depends, of course, on its remoteness and to a less degree on its environment. The inverse square law appears to be followed fairly exactly in the open for average sounds such as those of motor vehicles. In a room or a tunnel, the law does not hold and a noise sounds louder than it would outside, owing to the building up of the sound level by multiple reflection. Similar conditions prevail in a narrow busy street and contribute to the noise discomfort of the occupants in the upper stories, though to a pedestrian the noise of, say, a passing car is but little louder than in an open space. Incidentally, drivers of cars are familiar with the sudden access of high-pitched components from the engines, exhausts or tyres of their cars as they pass reflecting walls or fencing or even minor way-side objects such as tree trunks or telegraph poles.

One has also to remember that the path of a sound may appreciably modify its composition. For example, the high-frequency components may be abnormally reflected or absorbed as compared with lower notes which tend to pass through or round obstacles. Even in the open, a hedgerow or a barrage of trees may, to a limited extent, so serve as a muffler of traffic noise. The highpitched components of a sound may further be selectively enfeebled in passing over different types of ground, for which the sound absorption may be three or four times as much for high notes as for low. To judge by experience, the absorption figures for newly fallen snow must be rather high, though I am not aware that they have been measured. High-frequency components may also be selectively absorbed by the air itself if it is humid. Knudsen has shown that the effect is due to interaction between the oxygen and water molecules, the nitrogen playing no part. Incidentally, he estimates that if we lived in an atmosphere of oxygen at a humidity of about 20 per cent, the high notes of the violin and piccolo would be completely inaudible 50 yards away.

(To be continued.)

\title{
The Sex Ratio*
}

\author{
By Prof F. A. E. Crew
}

$\mathrm{T}^{\mathrm{H}}$ $\mathrm{HE}$ subject of the numerical proportions of the sexes in a population necessarily appeals to so many interests that it is not surprising to find that considerable attention has been paid to it. But so complicated are the problems that cluster around it that even yet our understanding of the significance of the sex ratio is still very incomplete. Recent developments in cyto-genetics have removed many of the difficulties that have surrounded this subject, so that it is possible now to re-examine the problem more hopefully.

The Registrar-General's Report for 1935 shows that the secondary sex ratio was $105: 100$; that

\footnotetext{
* From the presidential address for Section D (Zoology) of the British Association, delivered at Nottingham on September 2.
}

the sex ratio among those babies who died during the 7th-9th months of intra-uterine life was $110: 100$; that there is a remarkable swing in the sex ratio, a numerical preponderance of males amongst the earlier age groups of the population giving place to a numerical equality of the sexes amongst the 15-19 year olds, whilst amongst the 20-24 year olds the females actually begin to outnumber the males; and thereafter, as age group succeeds age group, this female numerical ascendancy progressively increases until, among the 85 's and over, there are more than twice as many women as men.

This swing in the sex ratio from high to very low is shown to be the result of a sexually selective 
mortality, for the mortality tables make it clear that at all ages relatively more males are removed from the population by death.

A consideration of these and similar facts ultimately leads to the conclusion that in the case of man, for some reason or other, the male, in virtue of his maleness, is less viable than the female, and that, in unfavourable circumstances, both pre-natally and post-natally, the male, because of this greater inherent fragility, suffers more easily and more severely than does the female, and is removed from the population by death in greater numbers. Furthermore, since this selective elimination of the male occurs before, as well as after, birth, it follows that the primary sex ratio is probably considerably higher than the secondary sex ratio.

A comparison of the secondary sex ratio in different countries, in town and country, as affected by migration, amongst legitimates and illegitimates, amongst whites and coloured, living under the same conditions, in different social strata, and in its relation to infantile mortality would seem to show that the whole course of sex mortality in pre-natal life, in infancy, and in all subsequent age periods is consistent with the view that the male in man is the inherently weaker sex, more prone on account of his relative constitutional weakness to developmental anomalies, to congenital debility and to death from diseases of all kinds.

Male must be contrasted with female in an attempt to discover the cause of this, and a study of the sex ratio in other mammals, birds and insects, wild and domesticated, both in the open and under the controlled conditions of experimentation, must be made, for, in this matter of the sex ratio, to know only man is to understand nothing.

Male differs from female in genetic constitution. In the case of man the male is the heterogametic sex. This being so, it follows that in the homogametic female a mutant recessive gene in one $X$ can be cancelled out by its wild-type dominant allele in the other, whereas the same recessive gene in the single $X$ of the heterogametic individual is unchecked and unrestrained and is expressed to produce its full effect. Upon this firm basis of ascertained fact, the sex-linked lethal theory, which seeks to account for the sexually selective mortality and the swing in the sex ratio, has been built.

It is clear that genetic lethals exist in considerable numbers in all animal and plant stocks that have been subjected to genetical experimentation. They are genes which can be mapped and which have an effect upon the secondary sex ratio that can be predicted. But since differences in chromosome constitution may imply more than a difference in respect of sex-linked lethals, they may also mean a difference in genic balance. It may be that this difference is itself the cause of unequal mortality, though it is difficult to regard the male as being less well-balanced genically since he has endured as long a course of selection as has the female, and it would be expected that dosage compensation would ensure a proper balance in each sex regardless of dosage ratios.

There are other genetic differences between the sexes which are sex-limited and not sex-linked. It is established that many defects and derangements in man, formerly regarded as recessives, are partial irregular dominants, and that many of these are more often and more completely expressed in the male than in the female. Many characters previously regarded as sex-linked are now known to be sex-limited, being expressed only in the male.

There are other differences, metabolic and physiological, which quickly appear in development and which give rise to endocrinological differences which, when once established, take charge of the further differentiation and the maintenance of sexuality in the higher forms. The initial genetic constitution would seem to determine which of two alternative types of differentiation shall occur and, with the incoming of the gonad and the rest of the endocrine system, maleness or else femaleness becomes finally and firmly established. These two states are to be distinguished by sustained differences in oxidation rate. Experiment has shown that the higher metabolic rate of the male renders him less resistant to unfavourable conditions and more prone to death.

A survey of what is known of the sex ratio amongst livestock and laboratory animals shows that, in general, the male amongst them shares with the male of man a relative frailty and endures a selective elimination both before and after birth.

The figures for birds are somewhat confusing. As a whole, they seem to show that it is the heterogametic sex (the female in birds) upon which death falls more heavily pre-natally. If this is so, it can at once be decided that in the heterogametic mechanism itself a factor of importance is to be found.

As a general rule, the males of all groups, except those derived from wide crosses in which genic balance is more likely to be unusual, appear to show a relatively low viability, irrespective of their homo- or heterogamety, and the difference in the death rates of the sexes appears to be as much correlated with sexuality itself as with any par. ticular type of chromosome or gene equipment. That this should be so is perhaps not surprising 
when the relative reproductive values of the sexes are compared. The major task of one generation of gamete producers is the production, economically and efficiently, of a succeeding generation that numerically will be in harmony with the conditions and resources of the habitat. That of the females of a generation is the production of the requisite number of ova ; that of the males the production of spermatozoa in numbers sufficient to make the fertilization of every available egg highly probable. The number of spermatozoa required will be determined by many factors-for example, the variety of the fertilization process, the pre-natal and post-natal relations of mother and offspring, the relationship of male to female in respect of parentage. If the male is merely a fertilizing agent, then economy and efficiency are observed if the male dies in coitu or is for other reasons shorter-lived than the female, so long as there are more or less equal numbers of males and females of the age when fertilization occurs. If the male is concerned with the protection of and food-finding for the female and her young, then the length of life of the male might be expected to be related to the duration of the period of dependency of the young upon the parents and of the female upon the male, and it might reasonably be assumed that when the male has served his purpose he would be removed so that savings in food energy could be effected and used for further reproduction.

Reference has already been made to the fact that in the Registrar-General's Report for 1935 the sex ratio most nearly approached equality amongst those in the population aged 15-19 years. In the Report on the Census of Scotland, 1931, table 31 , vol. 2 , it is seen that in this human population, though between the ages of $0-14$ there were more males than females and between the ages of 20-100 there were more females than males, the sex ratio of those in the population between the ages of 15 and 19 years was equality. It can be stated, therefore, that in the case of these human populations, the sex ratio is equality only amongst those who stand at the threshold of their reproductive prime. This fact is surely not without significance. The age group in which the sex ratio is equality consists of those who, biologically if not socially, are newly equipped for ardent reproduction. Amongst them there is no surplus: there are equal numbers of males and females. If, during the biological evolution of man, pair-mating attached to itself a definite and positive value, it would be expected that all the mechanisms concerned in the establishment of a sex ratio of near equality among the 14-19 age group would, through selection, come ultimately to be related harmoniously to this end.
Implied in this suggestion is yet another : that in the case of any population of living things and under the conditions that exist in any given place and at any given time, there is an optimum sex ratio amongst those of the ages associated with the fullest expression of the reproductive function, and that through selection all the mechanisms, whatever they may be, which influence this are fashioned into harmony with this 'reproductive' sex ratio. It is necessary, therefore, to discuss the meaning in biological philosophy of mutation, sex and heterogamety, all of which are intimately concerned.

Mutation is a mechanism that has become adapted and elaborated for the provision of material possibilities of evolutionary movement. It takes the form of the replacement of one gene by an allelomorph-the substitution of a gene that, having been tested and found worthy, has come to be in harmony with the rest of the genotype, and through this with the conditions of the external environment, by another, the merits of which have yet to be determined. More often than not, therefore, mutation implies a disturbance of an equilibrium within the genotype itself, and between this and the external environment. It is usual, therefore, to find that mutation leaves the genotype less in harmony with the existing external conditions than was that which it has replaced. Mutation, the inception of a new heritable variation, thus usually equips its possessors with a handicap, imposing on them a disadvantage that can range from inconvenience to complete lethality.

Sex is the mechanism that has become adapted for the dispersal of a mutant gene amongst a population. Through its exercise a new gene can become incorporated into a variety of genotypes, and thus given the opportunity of finding itself associated with other genes with which it can interact. It is established that the quality of the action of a gene is largely determined by this interaction with others, for, as judged by its effects upon the life processes of the zygote, it can exhibit disadvantageous properties when in one gene association, advantageous when in another. For the quiet dispersal of a mutant gene in this way it is necessary that it should be recessive, initially at least, to the gene that it has displaced, for then it can pursue a cryptomeric existence for a considerable period of time.

If the great usefulness of sexuality lies in the opportunities it provides for variety in gene recombination and for the exercise of selection, then its advantages will be best exploited when, among those about to reproduce, there is a sex ratio of equality. This observation would not seem to apply to those instances in which gene combinations that are common or are exceedingly rare are 
concerned, but a sex ratio of equality among the parents would seem to provide the greatest variety of recombinations in the offspring in the case of gene combination of intermediate rarity. Be this as it may, a device for the production of a sex ratio of equality has certainly been elaborated.

Heterogamety is a mechanism that has become adapted for the production of a primary sex ratio of equality. In its evolution in the higher forms it has taken the form of the replacement in one sex of an $X$-chromosome by a wholly or largely non-homologous $Y$-chromosome. The heterogametic sex, therefore, now possesses one $X$ chromosome, the homogametic, two. An indirect result of this evolution has been that a recessive mutant gene in the differential segment of the $X$-chromosome is at once uncovered in the case of the heterogametic individual, and so, if in its action such a gene is disadvantageous, deleterious or lethal, to it no time is allowed for the finding of modifying company and for the pursuit of its own evolutionary development. It is expressed and tested within a very short time of its first appearance, and should it cripple or kill, it is the heterogametic sex that is affected. In this way the sex ratio becomes modified, for the heterogametics either die before birth or else their early post-natal mortality is greater than is that of the homogametics. It is somewhat surprising that so few sex-linked lethals have so far been discovered in mammals. It would seem that the differential segment of the $X$ is relatively insignificant and that the cross-over portion, which could not yield a differential mortality since its genes would not automatically be expressed in the male, is relatively large.

It is thus possible to look upon the inequality in capacity for continued life between the sexes as being partly of the nature of an evolutionary oversight due to a lag in the development of a harmonious relationship between the mechanisms of mutation and heterogamety. But this disharmony has been repaired by the invention of a supplementary device which can provide a compensatory primary sex ratio, high in those species with male heterogamety, low in those in which the heterogametic sex is the female. It is established that in many, though not in all, mammalian stocks, the primary sex ratio is much higher than is the secondary, and it is in such stocks that there is much sexually selective mortality operating to the disadvantage of the heterogametic sex. This being so, it seems reasonable to entertain the view that these three variables-the primary sex ratio, a sexually selective pre-natal and early post-natal mortality and the optimum reproductive sex ratio -are somehow related, the dimensions of the first being connected with the amount of the second.
Should this prove to be the case, then it would follow that in general the greater the incidence of mutation, the more common the sex-linked recessive lethals and the greater the difference in the sex incidence of mortality in adolescence in a stock with male heterogamety, the higher will be the primary sex ratio; and, conversely, the rarer mutation is, the fewer the lethals and the less the difference in the sex incidence of mortality between conception and reproductive prime, the nearer to equality will this primary sex ratio be.

This suggestion, of course, demands that there should be genes which affect the functioning of the heterogametic mechanism, and also that it should be possible, by continued selection, to modify the primary sex ratio of a stock. This will be equality when the heterogametic sex elaborates its two kinds of gametes, $X$ - and $Y$-chromosomebearing respectively, in equal numbers, and when both of these are equally functional in fertilization. Conversely, the primary sex ratio will be removed more or less from equality if and when the two forms of gametes are not produced by the heterogametic sex in equal numbers, or when, between these two forms, there is functional inequality. The fact that in those instances where the primary sex ratio is not equality it is the $Y$-bearing gamete that is either produced in greater numbers or is greatly advantaged in fertilization, so that more $X Y$ than $X X$ gametes are produced, is of great interest in view of the observed fact that it is the $X Y$ zygote that suffers more through the action of sex-linked lethals.

It has been shown to be possible, by continued selection within an animal stock, to produce high and low sex ratio strains, and thus it would appear that there are genes which can be concentrated in a genotype which, in their action, influence the heterogametic mechanism affecting either the relative production of the two kinds of gametes produced by the heterogametic sex or else their relative functional ability. If, as seems to be the case, the male in many forms and irrespective of his chromosome constitution is the weaker sex, then in those instances in which the male is homogametic an excess of $X$-chromosome-bearing ova is demanded from the heterogametic females or else there must be some form of selective fertilization, the $X$-ova being more often or more readily fertilized.

That genes which lead to the production of $X$ - and $Y$-bearing gametes in unequal numbers do exist is shown very clearly indeed by the work of Sturtevant and others. One such gene was discovered as long ago as 1922 (Morgan, Bridges and Sturtevant, 1925) in a strain of Drosophila affinis in which occasional males were found to produce families consisting almost entirely of females. A 
definite $X$-borne gene was suspected. Gershenson (1928) found a similar gene in Drosophila obscura, and showed that it was indeed resident in the $X$-chromosome. A male carrying this gene produces very few sons, regardless of the genetic nature of his mate. More recently (1936) Sturtevant and Dobzhansky have found that this gene has a very wide geographical distribution in both races of Drosophila pseudo-obscura, that it is sex-linked, lying in the right arm of the $X$-chromosome, and being associated with a small inversion. Cytological study has shown that in these cases the $X$-chromosome undergoess equatorial division at each meiotic division, whilst the $Y$-chromosome degenerates, with the result that a male carrying this gene produces nearly all $X$-sperm instead of the usual 50 per cent. It is to be expected, of course, that a sex ratio gene of this kind would be discovered only if its effects upon the sex ratio were profound. But the existence of such genes permits us to assume that other genes of the same kind, having less severe effects upon the heterogametic mechanism, also exist and are responsible for minor distortions of the sex ratio. If such genes do exist, then, of course, they can be incorporated into, or extruded from a genotype, and upon them selective agencies can work their will. These sex ratio genes may perhaps provide a partial explanation of the observation that hybridization commonly is attended by marked distortions of the secondary sex ratio.

But all this is so much speculation, and the only justification for toying with such ideas is that criticism may be aroused and experimentation launched. I have presented evidence to show that three possible causes of sex differences in mortality have to be considered: (1) sex-linked lethals, (2) sex-limitation of defects and derangements, and (3) sex-dimorphic physiological and endocrinological differences. It seems probable that sexlinked lethals play only a minor part and that the defects and derangements that have come to be manifested only or more completely in the male owing to his relative unimportance in respect of propagation, constitute the major cause, though as yet too little is known of sex differences in respect of hormones and their effects to permit us to regard these as unimportant.

\section{The British Association at Nottingham}

\section{$\mathrm{T}$} HE British Association opened at Nottingham on Wednesday, September 1, at a time when local residents feared that a pleasant spell of very fine weather was to be rudely broken; but after a severe storm had passed over, the Association settled down to enjoy days of bright sunshine. The attendance of more than two thousand members is regarded as quite satisfactory, and there is no doubt that those visiting the city for the first time were definitely impressed by the delightful setting of the University College and the accommodation it provided. The opening presidential address on the history of evolutionary thought was well supported, and Prof. W. W. Watts, in moving a vote of thanks, suggested that the fact that Sir Edward Poulton had a son who was president of a Section provided a proof of natural selection.

The presidential addresses to the Sections were crowded. Mr. H. G. Wells had some striking things to say about education, but, so far as one could judge, they served only to increase the admiration and adulation of the professional members in his audience. His contentions were, in a way, supported by Prof. E. J. Salisbury's address to Section K (Botany), which one member described as "short, simple and lovable". They were also supported by speakers at a later discussion on the educational function of a university. Prof. F. A. E. Crew's presidential address was regarded as one of the most stimulating of the whole meeting. It was, however, in Section A that records were broken in an extraordinary manner by Dr. G. W. C. Kaye. Here, for the first time, a president took acoustics as the subject of his address, and delivered it, appropriately enough, in a lecture theatre designed by Prof. E. H. Barton just before his death. Moreover, the address was for the first time illustrated by experiments, in which a selection of some forty motor-horns were used with great effect to produce another record in noise. Perhaps it was the general appeal of the subject which caused Section $A$ to be crowded out and to provide a further record in the nature of a repeat performance of the experiments later in the day. Section A must also be credited with another record, which it certainly did not seek ; one of its most pleasant social activities appeared in the programme under the heading "mystery trip".

The general discussions had clearly been well planned. Dr. F. L. Pyman's presidential address to Section B opened a stimulating symposium on various aspects of chemotherapy, while, at the same time, local geologists, headed by Prof. H. H. Swinnerton, had the pleasure of describing the geology of the Nottingham district to Section C. 